\title{
High-Temperature Thermoelectric Power Studies of Ni-Mg Ferrites
}

\author{
Abdul Gaffoor, Dachepalli Ravinder* \\ Department of Physics, Osmania University, Hyderabad, India. \\ Email: *ravindergupta28@rediffmail.com \\ Received March $8^{\text {th }}, 2012$; revised April 11 $1^{\text {th }}, 2012$; accepted April 25 $5^{\text {th }}, 2012$
}

\begin{abstract}
Thermoelectric Power studies of Ni-Mg ferrites having chemical formula $\mathrm{Ni}_{1-\mathrm{x}} \mathrm{Mg}_{\mathrm{x}} \mathrm{FeO}_{4}(\mathrm{x}=0.2,0.4,0.6$ and 0.8$)$ were investigated from room temperature to well beyond Curie temperature by the differential method. The Seebeck coefficient is negative for all the composition. It clearly speaks that all the considered ferrite compositions behave as n-type semiconductors. Plots of Seebeck coefficient (S) versus temperature shows maximum at Curie temperature. The values of the charge carrier concentration have been computed from the observed values of Seebeck coefficient. The electrical properties of the Ni-Mg mixed ferrites have been measured at room temperature by two-probe method. On the basis of these results an explanation for the conduction mechanism in Ni-Mg mixed ferrites is suggested.
\end{abstract}

Keywords: Electrical Properties; Sintering; Thermoelectric Power; Ni-Mg Ferrites

\section{Introduction}

Hall effect and thermoelectric power studies are widely used in the interpretation of the conduction mechanism in semiconductors. The result of interpretation of Hall effect reveals more straight forwarding precise results. However, in the case of low mobility semiconductors such as ferrites, it is sometimes difficult to measure the Hall effect, in such cases the study of thermoelectric measurements is the only alternative. Moreover the measurement of thermo-e.m.f. is simple and its sign gives vital information about the type of conduction in semiconductor whether they are n-type or p-type. Magnesium substituted ferrites have been used in many electronic devices for high frequency because of their high electrical resistivity, high Curie temperature and low cost.

The dielectric properties of Ni-Mg ferrites have been studied in detail [1]. As per author's knowledge no information is available on thermometric power studies of mixed Ni-Mg ferrites in the literature. Moreover, there is a need for a thorough study of thermoelectric power studies of magnesium substituted nickel ferrites as a function of composition and temperature. The results of such a study are presented in this paper.

\section{Experimental Details}

\subsection{Sample Preparation}

The polycrystalline magnesium substituted Nickel fer-

${ }^{*}$ Corresponding author. rites having the compositional formula $\mathrm{Ni}_{1-\mathrm{x}} \mathrm{Mg}_{\mathrm{x}} \mathrm{FeO}_{4}(\mathrm{x}=$ $0.2,0.4,0.6$ and 0.8$)$ were prepared by double sintering ceramic method and the samples are annealed at $800^{\circ} \mathrm{C}$ for $5 \mathrm{hr}$. Final sintering of the specimens was carried out at $1200^{\circ} \mathrm{C}$ for $5 \mathrm{hr}$, the sintering atmosphere was being air. The details of the method of the preparation have been given in earlier publication [2].

\subsection{Measurements}

The Seebeck coefficients were measured by a differential method $[3,4]$ from room temperature to well beyond $\mathrm{Cu}-$ rie temperature. The temperature gradient across the sample was measured using two pairs of copper constan$\tan$ thermocouples. The sample was mounted on top of two well-separated copper blocks with silver paint. The temperature difference between two ends of the sample was kept at $10^{\circ} \mathrm{C}$ throughout the measured temperature range. To eliminate the effects of the reference leads, the absolute thermoelectric power of $\mathrm{Cu}$ was subtracted from the measured thermoelectric voltage. A Keithly 181 nano voltmeter was used for the voltage measurements.

The thermoelectric power or Seebeck coefficient (S) was calculated using the relation

$$
\mathrm{S}=\frac{\Delta \mathrm{E}}{\Delta \mathrm{T}}
$$

where $\Delta \mathrm{E}$ is the thermo e.m.f. produced across the sample due to the temperature difference $\Delta \mathrm{T}$. The electrical 
conductivity of the samples has been measured at room temperature by two-probe method [5] using a Kiethly electrometer model 6517A. The electrical conductivity $(\sigma)$ of the Ni-Mg ferrites under investigation has been computed using the formula,

$$
\sigma=\frac{\mathrm{It}}{\mathrm{VA}}
$$

where $I$ is the current passing through the specimen in amperes, $\mathrm{V}$ is the voltage applied to the specimen in volts, $\mathrm{t}$ is the thickness of the sample in centimeters and A denotes the area of sample in square centimeters. The Curie temperature $T_{c}$ of the sample was determined by gravity method [6].

\section{Results and Discussions}

\subsection{Composition Dependence of Lattice Parameter}

X-ray diffraction patterns for all ferrites under investigation have been obtained using $\mathrm{Cuk}_{\alpha}$ radiation of Rigaku DMAX II X-ray diffractomer. The lattice parameter of the mixed ferrites was calculated from d-spacing values. The variation in the lattice parameter with magnesium content is shown in Figure 1. It can be seen from the figure that the lattice parameter varies linearly with the magnesium ion content. A similar linear variation has also been observed in $\mathrm{Zn}-\mathrm{Mg}-\mathrm{Cu}$ [7] and Co- $\mathrm{Zn}$ [8] ferrites.

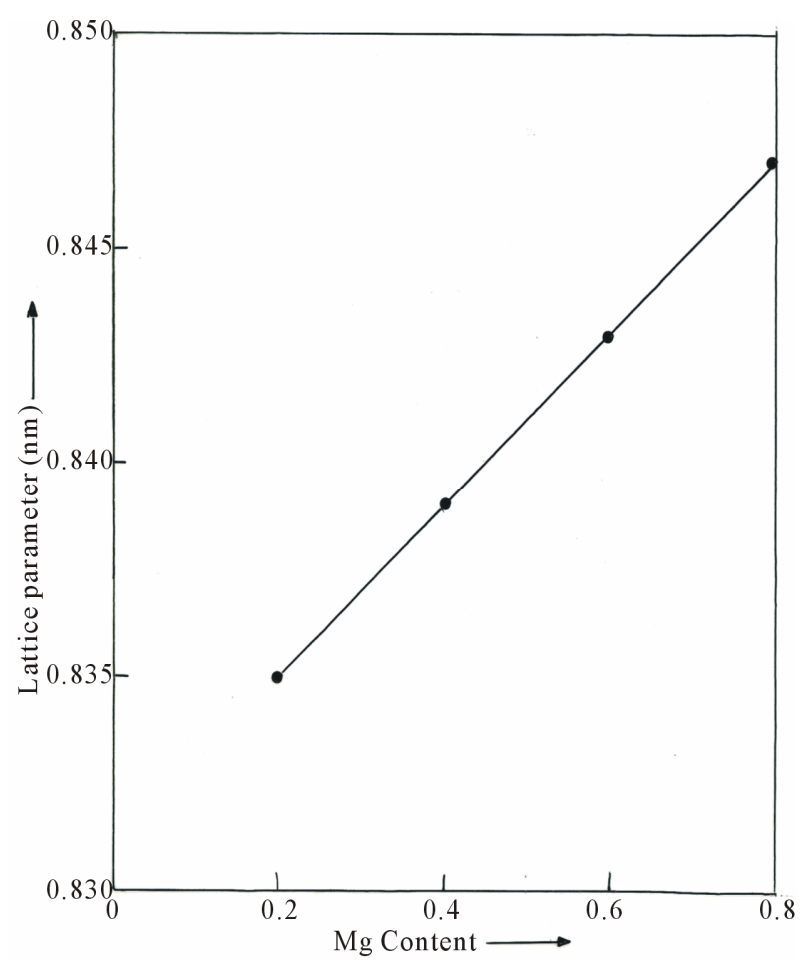

Figure 1. Variation of lattice parameter with magnesium content.

\subsection{Composition Dependence of Seebeck Coefficient}

The value of Seebeck coefficient (S) at $310 \mathrm{~K}$ computed from the measured values of thermo-e.m.f. is given in the Table 1. It can be seen from the table that the sign of Seebeck coefficient is negative for the Ni-Mg ferrites. On the basis of its negative sign, the magnesium substituted Nickel ferrites have been classified as n-type semiconductors. It can also be seen from the table that the value of Seebeck coefficient varies from -189 to $-286 \mu \mathrm{V} / \mathrm{K}$ as the magnesium content increases from 0.2 to 0.8 moles.

\subsection{Temperature Dependence of Thermoelectric Power}

The variation of the thermoelectric power (S) with temperature is shown in the Figure 2. It can be seen from the figure that the value of thermoelectric power for all $\mathrm{Ni}-\mathrm{Mg}$ ferrites increases with increasing temperature up to a certain temperature, which is designed as $\mathrm{T}_{\mathrm{s}}(\mathrm{K})$. However, beyond this temperature the value of $\mathrm{S}$ starts decreasing with increasing temperature. The negative value of thermoelectric power found over the entire temperature range studied shows that the majority charge carriers are electrons. A similar variation of thermoelectric power with temperature was observed in $\mathrm{Mg}-\mathrm{Cr}$ [9] and Lithium ferrites [10]. The values $\mathrm{T}_{\mathrm{s}}(\mathrm{K})$ for each composition are given in the Table 1. The Curie temperature $T_{c}(K)$ values are also included in table for comparison. It can be seen from the table that the values $T_{s}$ $(\mathrm{K})$ and $\mathrm{T}_{\mathrm{c}}(\mathrm{K})$ are close, thereby indicating that the change in the behavior of the thermoelectric power with temperature may be due to magnetic transition, where the material becomes the paramagnetic. Thus, it is clear that in case of $\mathrm{Ni}-\mathrm{Mg}$ ferrites the non-magnetic property under study (thermoelectric power) is exhibiting a clear-cut and well-defined transition at the Curie temperature, like the magnetic property such as susceptibility, permeability and spontaneous magnetization. The value of thermoelectric power is maximum at $\mathrm{T}_{\mathrm{c}}(\mathrm{K})$. This clearly indicates

Table 1. Thermoelectric power data on mixed Ni-Mg ferrites.

\begin{tabular}{ccccc}
\hline Sl.No & $\begin{array}{c}\text { Ferrite } \\
\text { composition }\end{array}$ & $\begin{array}{c}\text { Seebeck } \\
\text { coefficient } \\
\boldsymbol{\mu V} / \mathbf{K}\end{array}$ & $\begin{array}{c}\text { Seebeck } \\
\text { coefficient } \\
\text { transition } \\
\text { temperature } \mathbf{T}_{\mathbf{s}}(\mathbf{K})\end{array}$ & $\begin{array}{c}\text { Curie } \\
\text { temperature } \\
\mathbf{T}_{\mathbf{c}}(\mathbf{K})\end{array}$ \\
\hline 1 & $\mathrm{Ni}_{0.8} \mathrm{Mg}_{0.2} \mathrm{Fe}_{2} \mathrm{O}_{4}$ & -286 & 762 & 760 \\
2 & $\mathrm{Ni}_{0.6} \mathrm{Mg}_{0.4} \mathrm{Fe}_{2} \mathrm{O}_{4}$ & -254 & 710 & 708 \\
3 & $\mathrm{Ni}_{0.4} \mathrm{Mg}_{0.6} \mathrm{Fe}_{2} \mathrm{O}_{4}$ & -218 & 660 & 662 \\
4 & $\mathrm{Ni}_{0.2} \mathrm{Mg}_{0.8} \mathrm{Fe}_{2} \mathrm{O}_{4}$ & -189 & 615 & 610 \\
\hline
\end{tabular}




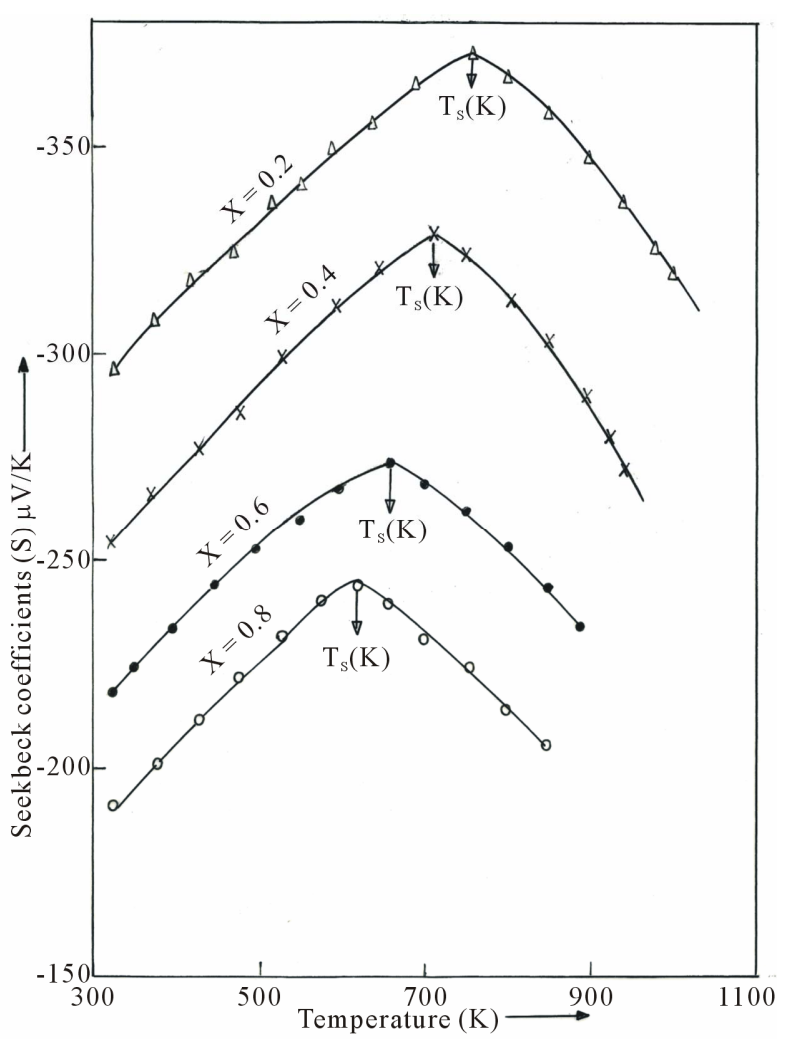

Figure 2. Plot of Seebeck coefficient (S) versus temperature for mixed $\mathrm{Ni}_{1-\mathrm{x}} \mathrm{Mg}_{\mathrm{x}} \mathrm{Fe}_{2} \mathrm{O}_{4}$ Ferrites.

that the magnetic ordering has a marked influence on the thermoelectric property of these ferrite samples.

The variation of the Curie temperature $T_{c}(K)$ with magnesium composition is shown in Figure 3. It can be noted from the figure that the value of $T_{c}(K)$ decreases with increase of magnesium content. The decrease of Curie temperature with increase of magnesium content can be explained on the basis of the number of magnetic ions present in the two sub-lattices and their mutual interactions. $\mathrm{As}^{\mathrm{Fe}^{3+}}$ ions are gradually replaced by magnesium ions, the number magnetic ions being decrease at both sides, which also weakens the strength of $\mathrm{AB}$ exchange interactions of the type $\mathrm{Fe}_{\mathrm{A}}{ }^{3+}-\mathrm{O}^{2-}-\mathrm{Fe}_{\mathrm{B}}{ }^{3-}$. Thus the thermal energy required to offset the spin alignment decrease, thereby decreasing the Curie temperature. A similar decrease of the $T_{c}(K)$ with the composition was also observed by Zaki [11] in case of Mg-Zn ferrites and Ravinder and Latha in Mn-Zn [12] ferrites.

\subsection{Composition Dependence of Electrical Conductivity $(\sigma)$, Carrier Concentration (n) and Mobility $(\mu)$}

Table 2 gives the experimental values of electrical conductivity and Seebeck coefficient values at room temperature. The carrier concentration for these ferrites was

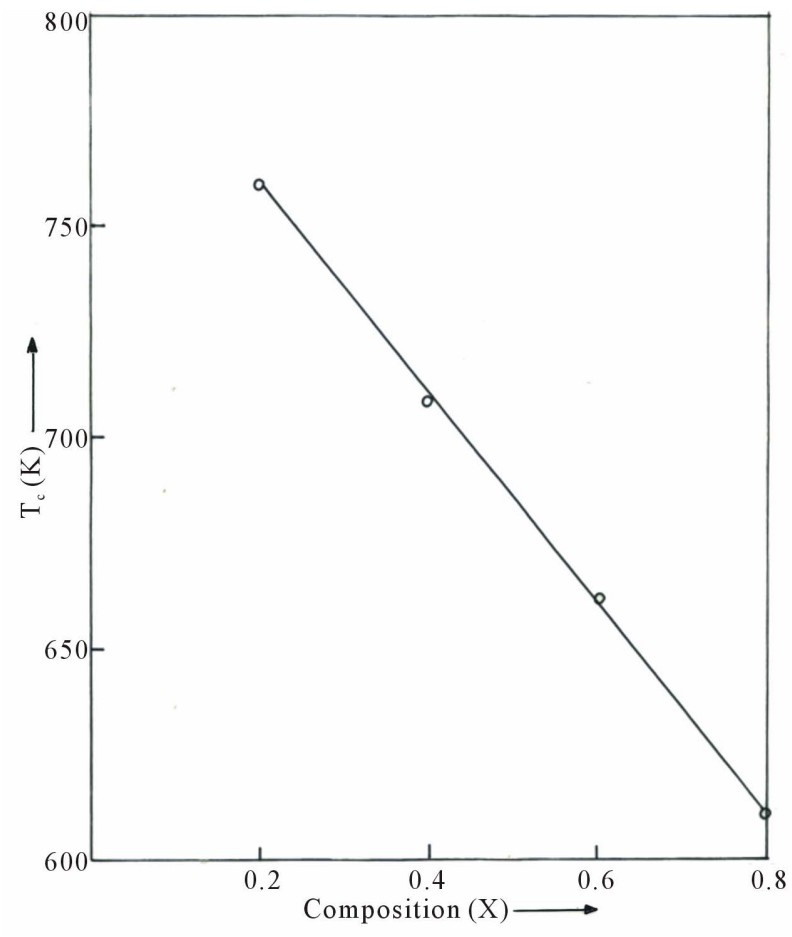

Figure 3. Variation of Curie temperature $T_{c}(K)$ with composition.

Table 2. Electrical transport data of Ni-Mg ferrites.

\begin{tabular}{|c|c|c|c|c|}
\hline Sl.No & $\begin{array}{c}\text { Ferrite } \\
\text { composition }\end{array}$ & $\begin{array}{c}\text { Electrical } \\
\text { conductivity }(\sigma) \\
\mathrm{Ohm}^{-1} \mathrm{~cm}\end{array}$ & $\begin{array}{c}\text { Charge } \\
\text { carrier } \\
\text { concentration } \\
\text { (n) } 10^{20} / \mathrm{cm}^{3}\end{array}$ & $\begin{array}{c}\text { Charge } \\
\text { carrier } \\
\text { mobility }(\mu) \\
\mathbf{c m}^{2} / \mathbf{V s}\end{array}$ \\
\hline 1 & $\mathrm{Ni}_{0.8} \mathrm{Mg}_{0.2} \mathrm{Fe}_{2} \mathrm{O}_{4}$ & $1.52 \times 10^{-5}$ & 5.50 & $1.72 \times 10^{-5}$ \\
\hline 2 & $\mathrm{Ni}_{0.6} \mathrm{Mg}_{0.4} \mathrm{Fe}_{2} \mathrm{O}_{4}$ & $4.86 \times 10^{-6}$ & 3.97 & $7.6 \times 10^{-6}$ \\
\hline 3 & $\mathrm{Ni}_{0.4} \mathrm{Mg}_{0.6} \mathrm{Fe}_{2} \mathrm{O}_{4}$ & $6.84 \times 10^{-7}$ & 3.48 & $12.22 \times 10^{-7}$ \\
\hline 4 & $\mathrm{Ni}_{0.2} \mathrm{Mg}_{0.8} \mathrm{Fe}_{2} \mathrm{O}_{4}$ & $8.12 \times 10^{-8}$ & 3.20 & $15.78 \times 10^{-8}$ \\
\hline
\end{tabular}

calculated using formula given by Morin and Gebella [13] and are rough estimated based on a simple 2 band model.

$$
\mathrm{n}=\mathrm{N} \exp \left(-\frac{\mathrm{Se}}{\mathrm{K}}\right)
$$

where $\mathrm{S}$ is Seebeck coefficient, e is charge of electron, $\mathrm{K}$ is Boltzmann constant and $\mathrm{N}$ is density of states or concentration of electronic levels involved in the conduction process.

The computed values of carrier concentration are included in Table 2. It can be seen from the table that the values of electrical conductivity decrease with the increase of magnesium content. This observation is in agreement with the reported by Rezlescu et al. [14] who found the resistivity of $\mathrm{Li}-\mathrm{Zn}$ increases with increase of zinc content. Among all the ferrites the specimen with composition $\mathrm{Ni}_{0.2} \mathrm{Mg}_{0.8} \mathrm{Fe}_{2} \mathrm{O}_{4}$ has a minimum value for 
the Seebeck coefficient and a minimum value for the carrier concentration.

The mobility $(\mu)$ of the charge carriers was calculated from the experimental values of the electrical conductivity $(\sigma)$ and carrier concentration (n)

$$
\sigma=\text { ne } \mu
$$

The values of the charge carrier mobility for the different composition are also included in the Table 2. It can be seen from the table that the specimen with the composition $\mathrm{Ni}_{0.8} \mathrm{Mg}_{0.2} \mathrm{Fe}_{2} \mathrm{O}_{4}$ exhibits the highest value of charge carrier mobility.

\section{Conclusion}

In the present investigation $\mathrm{Ni}-\mathrm{Mg}$ ferrites are classified as n-type semiconductors. Among all the ferrites the specimen with composition $\mathrm{Ni}_{0.2} \mathrm{Mg}_{0.8} \mathrm{Fe}_{2} \mathrm{O}_{4}$ exhibits the lowest value of Seebeck coefficient. This composition will be useful for technical application where low value of Seebeck coefficient material is required.

\section{Acknowledgements}

The authors are grateful for Prof. P. Kistaiah, Head, Department of Physics Osmania University, Hyderabad for his encouragement in research work.

\section{REFERENCES}

[1] J. Berchmans, R. Kalaiselvan, P. N. Selva Kumar and C. O. Augustin, "Structural and Electrical Properties of $\mathrm{Ni}_{1-x} \mathrm{Mg}_{x} \mathrm{Fe}_{2} \mathrm{O}_{4}$ Synthesized by Citrate Gel Process," Journal of Magnetism and Magnetic Materials, Vol. 279, No. 1, 2004, pp. 103-110. doi:10.1016/j.jmmm.2004.01.073

[2] Dr. D. Ravinder and T. Seshagiri Rao, "Electrical Conductivity and Thermoelectric Power of Lithium-Cadmium Ferrites," Crystal Research and Technology, Vol. 25, No. 8, 1990, pp. 963-969. doi:10.1002/crat.2170250820

[3] Z. Simsa, "Czech," Journal of Physics B, Vol. 16, 1996, pp. 919-921.

[4] V. D. Reddy, M. A. Malik and P. V. Reddy, "Electrical
Transport Properties of Manganese-Magnesium Mixed Ferrites," Materials Science and Engineering B, Vol. 8, No. 4, 1991, pp. 295-301. doi:10.1016/0921-5107(91)90050-6

[5] V. R. K. Murthy and J. Sobhanadri, "Electrical Conductivity of Some Nickel-Zinc Ferrites," Physica Status Solidi, Vol. 38, No. 2, 1976, pp. 647-651. doi:10.1002/pssa.2210380227

[6] D. Ravinder, "Electrical Properties of Lithium-Zinc and Lithium-Cadmium Ferrites," Thesis, Osmania University, Hyderabad, 1988.

[7] S. M. Yunus, H. S. Shim, C. H. Lee, M. A. Asgar, F. U. Ahmed and A. K. M Zakaria, "Neutron Diffraction Studies of the Diluted Spinel Ferrite $\mathrm{Zn}_{x} \mathrm{Mg}_{0.75-x} \mathrm{Cu}_{0.25} \mathrm{Fe}_{2} \mathrm{O}_{4}$," Journal of Magnetism and Magnetic Materials, Vol. 232, No. 3, 2001, pp. 121-132. doi:10.1016/S0304-8853(01)00224-4

[8] A. V. Ramana Reddy, G. Ranga Mohan, D. Ravinder and B. S. Boyanov, "High-Frequency Dielectric Behaviour of Polycrystalline Zinc Substituted Cobalt Ferrites," Journal of Materials Science, Vol. 34, 1999, pp. 3169-3176.

[9] P. P. Hankar, V. T. Vady, U. B. Sankpau, L. V. Gavail, R. Sasikala and I. S. Mulla, "Effect of Sintering Temperature and Thermoelectric Power Studies of the System $\mathrm{MgFe}_{2-\mathrm{x}} \mathrm{Cr}_{\mathrm{x}} \mathrm{O}_{4}$," Solid State Sciences, Vol. 11, 2009, pp. 2075-2079.

[10] T. E. Whall, N. Salerno, Y. G. Proykova, K. A. Misza and S. Mazen, Philosophical Magazine, Vol. 53, 1986, pp. L107-L111.

[11] Zaki, "The Influence of Zn Ions Substitution on the Transport Properties of Mg-Ferrite," Physica B, Vol. 404, 2009, pp. 3356-3362.

[12] D. Ravinder and K. Latha "Electrical Conductivity of Mn-Zn Ferrites," Journal of Applied Physics, Vol. 75, No. 10, 1994, pp. 6118-6120. doi:10.1063/1.355479

[13] F. J. Morin and T. H. Gebella, "Electrical Conductivity and Seebeck Effect in $\mathrm{Ni}_{0.80} \mathrm{Fe}_{2.20} \mathrm{O}_{4}$, , Physical Review, Vol. 99, No. 2, 1955, pp. 467-498. doi:10.1103/PhysRev.99.467

[14] N. Rezlescu, D. Condurhach, P. Petairu and E. Luca, "Resistivity and Curie Point of Li-Zn Ferrites," Journal of the American Ceramic Society, Vol. 57, No. 1, 1974, p. 40. doi:10.1111/i.1151-2916.1974.tb11360.x 